\title{
Constructing Creativity: Social Media and Creative Expression in Design Education
}

\author{
Jia-Xiang Chai ${ }^{1,2 *}$, Kuo-Kuang Fan ${ }^{2}$ \\ ${ }^{1}$ Guangdong Literature \& Art Vocational College, Guangzhou, Guangdong, CHINA \\ 2 Graduate School of Design Doctoral Program, National Yunlin University of Science and Technology, TAIWAN
}

Received 6 July 2017 - Revised 13 August 2017 - Accepted 17 September 2017

\begin{abstract}
Social media plays a role in the development of a personal knowledge system and personal creativity. This paper develops a theoretical model to analyze the relation between social media and creative expression in design education. Based on the flow theory, the generativity theory, and TAM, the paper collects data regarding the usability dimension of students in social media, and their creativity, and examines the proposed model through statistical software SAS9.4 to analyze the data. A correlation is seen between the usability dimension of social media and the creative expression dimension, with an especially significant positive connection between perceived ease of use and perceived usefulness, as well as capturing and challenging. The adoption intention of social media is positively correlated with creative expression, while the usability dimension of social media has positive correlation with broadenings and negative correlation with surroundings; however, neither is significant. This reveals that aimlessly accumulating knowledge through social media will not help students improve their creativity; instead, overusing social media hinders one from understanding the real world and gaining inspiration. The paper is conducive to better social media design and higher personal creativity.
\end{abstract}

Keywords: creativity, social media, usability, creative expression, design education

\section{INTRODUCTION}

Social media can break boundaries between the virtual world and reality due to its powerful media functions and people's social behaviors when using it, making the slogan "Social media is changing the world" (Solis \& Breakenridge, 2009) a reality. Overall, social media is catalyzing changes in our behaviors and habits (Yoo \& Alavi, 2001). Recent years have witnessed increased research on social media and students' learning behaviors, in particular, how to develop a personal knowledge system with social media, or how satisfaction and attitudes gained from social media usability influence students' studies (e.g., Lu, Hao \& Jing, 2016; Bennett, Bishop, Dalgarno, Waycott, \& Kennedy, 2012; Correa, Hinsley, \& De Zuniga, 2010; Eyyam, Menevi, \& Dogruer, 2011; Luckin et al., 2009; Mao, 2014). Learning is defined as seeking increased abilities to innovate and upgrade one's knowledge structure, and is more than mere knowledge accumulation (Lee, 2000). Such increased abilities represent "creativity", which sustains the progress of civilization. How well does social media promote our creativity, while changing the world and human behavior?

Currently, there are few research efforts concerning the individual use of social media to affect creativity. Gu (2016) discussed the connection between creativity and social media according to the originality, flow, and flexibility of creativity. Chai and Fan (2016) discussed the influence of social media technologies on the creative achievements of students in design education. Earlier, Peppler, and Solomou (2011) discussed how creative ideas emerge within a community and spread amongst its members. While Computers in Human Behavior is a scholarly journal dedicated to examining the usability of social media and human behaviors, it has seldom discussed creativity in the past 5 years. Over the past five years, it has published 1,868 articles on social media and human

(C) Authors. Terms and conditions of Creative Commons Attribution 4.0 International (CC BY 4.0) apply. \amy93938311@gmail.com Jia-Xiang Chai, Graduate School of Design Doctoral Program, National Yunlin University of Science and Technology, 123 University Road, Section 3, Douliou, Yunlin 64002, Taiwan,

(*Correspondence). $\nabla$ fankk@gemail.yuntech.edu.tw 


\section{Contribution of this paper to the literature}

- This paper develops constructing creativity model to study the social media and creative expression by incorporating perceived ease of use and perceived usefulness of the Technology Acceptance Model, and collects data to verify the proposed model.

- This paper reveals the correlation between the usability dimension of social media and the creative expression dimension, while not all the factors are correlated.

- $\quad$ This paper provides new input to learning creativity and product design combining social media and education.

behavior; however, less than $7 \%$ of the articles were related to "creativity". Prestigious journals of creativity research, such as The Journal of Creative Behavior and the Creativity Research Journal, pay more attention to "creativity" itself, and expound on various topics, such as human intelligence, cognition, and social or clinical analysis. As we learn from what is said above, this study employs its research results and the survey research method to understand the mutual effect between creativity and usability for undergraduates in China, with a major in design using social media, in order to provide new insights and offer new ideas for product design by combining social media and design education.

Western research on "creativity" mainly focuses on four aspects: creative work, creative process, creative individual, and creative as a system (Lee, 2000). In particular, the latter two have provided theoretical basis and methods for improving creativity through education. For learners, social media provides an enabling environment for knowledge learning and exchange after class. Csikszentmihalyi (1975) put forward the flow theory, which highlights the influence of internal and external environments on individual creativity. Epstein (1990) proposed the generativity theory, which is a predictive theory of creative behavior in individuals, and suggests that creativity is a skill that can be learned and measured (Epstein, 1996). The technology acceptance model (TAM) was put forward by Davis (1989); with the behavior intention model as the theoretical basis, this model explains the behavior of users when using technological products, and introduces three concepts - adoption intention (AI), perceived ease of use (PEU), and perceived usefulness (PU), which all affect the attitude and acceptance of users when using technology (Davis, 1989). Based on these two theories and one model (the flow theory, generativity theory, and the technology acceptance model), this paper proposes a theoretical model to study the usability dimension of social media and creativity, and collects data to verify the proposed model.

\section{LITERATURE REVIEW}

\section{Usability Dimension of Social Media: Adoption Intention (AI), Perceived Ease of use (PEU), and Perceived Usefulness (PU)}

Learning outside the classroom plays a key role in individual growth. Csikszentmihalyi (1990) argued that individual creativity comes from domains, fields, and interactions between people, while parents and teachers are the gatekeepers that bring us to these fields. Consistent with Csikszentmihalyi's (1996) systems model, creativity is being increasingly understood as a system, which is composed of individuals, knowledge domains, and a field of informed experts. Amid the increasingly popular Web 2.0 and mobile hardware products, social media provides an exclusive platform for continuous interaction between students, teachers, and friends in different domains and fields, meaning an environment that connects online and offline activities. This means that when widely used, social media becomes an important social environment factor in student learning and growth, which may have positive or negative impact on individual creativity.

The flow theory (Csikszentmihalyi, 1996; Nakamura \& Csikszentmihalyi, 2014) mentioned that the challenges and skills in social environments are the main factors influencing immersion. If the challenges are too difficult, users will lack control over the environment and feel anxious and frustrated. Instead, if the challenges are too easy, users will get bored and lose interest. Immersion occurs mainly when challenges and skills are balanced. Researchers have found that individuals are most likely to be immersed in the process of using social media, followed by reading and writing. This indicates that when the widespread use of social media becomes an important environmental factor, individuals will use social media to seek information, read, and write, which are behaviors with certain degrees of challenge and skill. As the degrees of challenges and skills are determined by the user's personal awareness, it means that the ease of use and usefulness of personal cognition will affect immersion ability (Fullagar \& Kelloway, 2009).

At the same time, researchers have integrated the flow theory and adoption intention into a theoretical framework, and discovered that adoption intention contributes to individual creativity changes and the usability 
Table 1. Three Core Competencies of the usability of social media

Perceived usefulness (PU) - Users' subjective cognition that social media tools are more effective and beneficial in enhancing communication, creative work, study, and other tasks.

Sample item: "Make my learning and creative expression more efficient"

Perceived ease of use (PEU) - Users' subjective cognition that social media tools can (Chen \& Li, 2010; Davis, 1989; Hsu \& help them satisfy their needs.

Sample item: "Most social media are easy to use."

Adoption intention (Al) - The possibility of users continuing to use different social

media tools and recommending them to colleagues.

Sample item: "I advise colleagues to use social media for learning in the future."

(Chen \& Li, 2010; Davis, 1989; Hsu \& Lin, 2008; Chan, 2014)

Table 2. Four Core Competencies of Creative Expression

Capturing (CA) - Preserves new ideas as they occur, finds places and times where new ideas can be easily observed, and uses dreams and daydreams as the sources of ideas.

Sample item: "I always keep a recording device by my bed at night."

Challenging (CH) - Takes on difficult tasks, sets open-ended goals, and effectively manages fear and stress associated with failure

Sample item: "When I set goals for myself, I make sure they're open-ended."

Broadening (BR) - Seeks training, experience, and knowledge outside current areas of expertise

Sample item: "I often read books outside my specialty."

Surrounding (SU) - Changes physical and social environments regularly, seeks out unusual stimuli or combinations of stimuli

Sample item: "I redecorate or rearrange my work environment regularly."

Note. From "Measuring and Training Creativity Competencies: Validation of a New Test" by Robert Epstein, Steven M. Schmidt, and Regina Warfel, 2008, Creativity Research Journal, 20(1), 7-12

of social media (Chang \& Zhu, 2011). According to literature, AI, PEU, and PU are within TAM, and are expected to play an important role in the usability dimension of social media (Table 1).

\section{Generativity Theory to Creative Expression: Challenging, Broadening, Capturing, Surrounding}

American psychologist Robert Epstein (1990) proposed the generativity theory after experimentation. This theory asserts that novel behavior is the result of dynamic interactions among previously established behaviors; in other words, new ideas result from interconnections among old ideas, meaning the theory focuses on the creative expression of individuals, the environment, and the education level of individuals. The Generativity Theory suggests, among other things, that creative potential in individuals is universal and possibly limitless. However, as creative expression tends to be discouraged in our culture, such expressions are relatively rare. This is true, in part, because creative expression depends on the mastery of certain competencies (or skill sets), which only a handful of people in our society - people who tend to resist socialization-ever learn. Epstein $(1996,2008,2012)$ developed tests that measure four essential competencies, capturing, challenging, broadening, and surrounding, which individuals require to be able to express their creativity (as show in Table 2). Backed by the research of Epstein, this study sets capturing (CA), challenging $(\mathrm{CH})$, broadening $(\mathrm{BR})$, and surrounding $(\mathrm{SU})$ as the components of the creative expression dimension.

\section{Design Education and Social Media}

Social media platforms are extensions of the Web 2.0 technologies that have emerged over the past 10 years to greatly transform online interactions (Jones and Gelb, 2010). Widely adopted digital media formats, as well as the ability to share, publish, and co-create with a variety of proprietary and open-source web tools and services, are widely available, and with fewer technical barriers. Opportunities for educators are plentiful in leveraging social media technologies to expand spaces for learning (Abel, 2015).

Given its characteristic of cross-disciplinary connections, design education is broadly defined as the instruction of theory and application in the creation of products, services, and communications. Generally, students majoring in design require a wide range of knowledge, good creativity, and an enabling environment for communication and exchanges. Recent research on social media and design education mainly focused on the education research of design studios (Gelb, 2015, Güler, 2015; Chai and Fan, 2016; Lim, 2015; Abel, 2015). Moreover, the survey of Moran et al. (2012) showed that faculty who teach humanities and arts have the highest usage rates of social media, while 


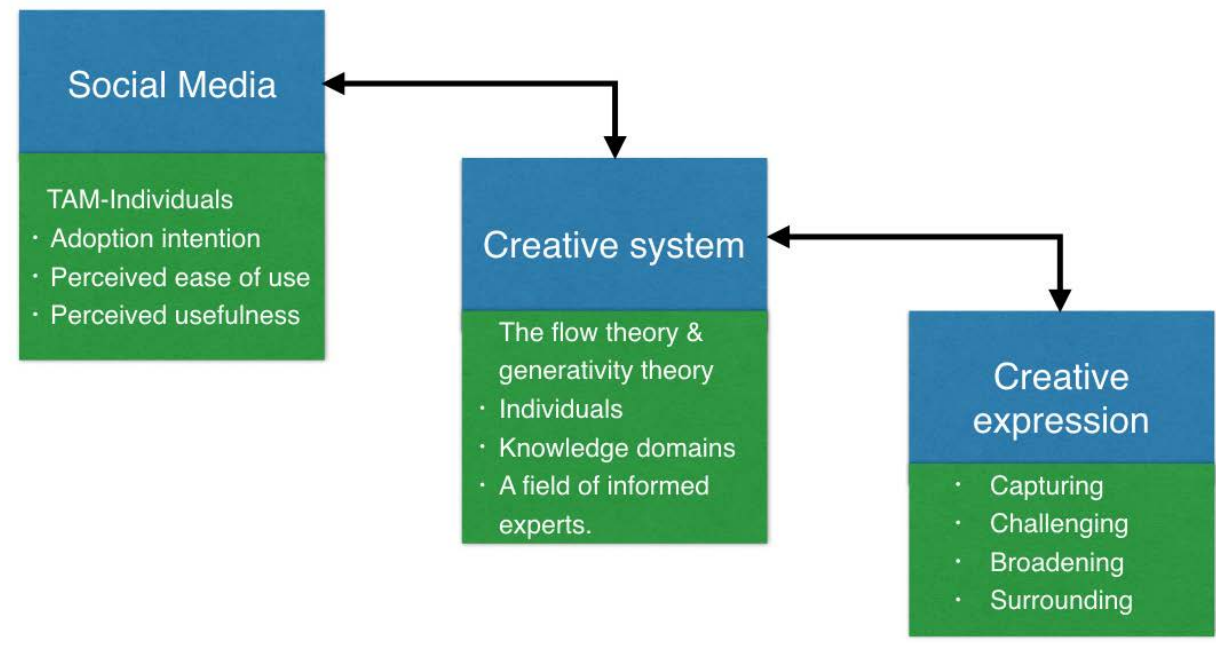

Figure 1. Constructing Creativity Research Proposal Model

those in the natural sciences have the lowest. This study targets students majoring in design for data collection, as a design major requires cross-disciplinary team cooperation and a high level of individual creativity.

This study defines social media as new technologies and applications that utilize the Internet and Web 2.0 technologies, and allows users to create and participate in various communities through various functions, such as communicating, sharing, collaborating, publishing, managing, and interacting. Combined with the characteristics of students majoring in design and the development of social media in China, this study focuses on following types of social media.

- Social networking tools, instant messengers running on smart mobile products, such as smartphones and tablets, e.g., Sina Weibo, WeChat (including public accounts), QQ, and LOFTER;

- Social publishing or sharing tools via Wikis, such as tablets, e.g., Wikipedia or Baidu Wikipedia, Baidu Zhidao;

- Social media tools for solution searching and knowledge sharing, such as smartphones, e.g., Zhihu, Fenda, Quora, Medium;

- Photo or video sharing tools, such as smartphones and tablets, e.g., Pinterest, Behance, Huaban, Youku;

- Online platform for open courses, such as smartphones and tablets, e.g., NetEase Online Open Courses;

- Online cooperation or editing tools, such as smartphones and tablets, e.g., Youdao Cloud Note, Evernote.

\section{RESEARCH MODEL AND METHODOLOGY}

\section{Research Model}

According to literature, this study proposes a research proposal model to understand the correlation between the usability of social media and individual creativity, as based on the flow theory, the generativity theory, and TAM. Figure 1 shows the theoretical research model. Individual creativity systems are extracted from the flow theory and the generativity theory, which links the usage of social media and creative expression. To sum up, this study hypothesizes significant correlation between the usability of social media and creative expression.

\section{Methodology}

Survey research is one of the most important areas of measurement in applied social research (Creswell, 2014), thus, this study adopts the survey method. The survey questionnaire is developed with two sections. The first section contains respondents' demographics (gender, education, university grade), and includes the question: What kind of social media platform will help you to learn or enhance your creativity. The second section includes seven factors: adoption intention, perceived ease of use, perceived usefulness, capturing, challenging, broadening, and surrounding. Regarding the questionnaire for the undergraduates with a design major in Guangzhou and 
Hangzhou cities; a total of 320 students participated in this survey. Following their participation, students could participate in a draw, where the prizes included mobile phone prepaid cards, 6 bottles of drinks, etc. Data are collected by a questionnaire containing 41 items, the majority of which are Likert items based on a scale from "strongly disagree" to "strongly agree". Other questions are asked for respondents' demographics. Concurrent and convergent validity (Campbell \& Fiske, 1959) of these measures are established through factor analysis, and are found to be at an adequate level. Reliability of the factors is established through Crobanch's alpha, and Canonical Correlation Analysis (CCA) (Kanti \& Bibby, 1979) are used to analyze the data.

\section{Research methods}

The questionnaire was strictly conducted according to the research design methods. Relevant literature was collected and sorted, and then, the first draft of the questionnaire was edited based on TAM, Epstein's research, and his ECCI-i scale; after completion, two professors and three design teachers from universities were invited to revise the content of the questionnaire, in order to improve face validity and content validity. Seven design students were invited to pre-test the questionnaire, which was subsequently revised; after a series of modifications, the formal questionnaire was completed for this study.

The collected questionnaires were checked for validity, and the valid recovery rate of effective questionnaires was calculated.

Next, according to the basic data of the collected samples, this study encoded the raw data into a computer, and used statistical analysis software SAS9.4 to explain the characteristics of the samples through descriptive analysis. This study used non-response bias to determine the representativeness of the samples, meaning we divided the sample into two parts according to the return time and used $\chi^{2}$ Testing to determine whether there was response bias between the two kinds of samples.

Finally, this study used factor analysis to test reliability and validity; if Crobanch's alpha was $>0.7$, then CCA analysis would continue to be used to verify the hypothesis of this study.

\section{Sample}

The following two criteria guide the sample selection of this study. First, only the undergraduate users of social media tools (e.g., WeChat, Sina Weibo, etc.) in a design major are qualified to participate in this survey. Second, this study surveys only the undergraduates of Guangzhou and Hangzhou for two reasons: (1) The applications of mobile Internet in the two cities are ranked among the top in China; (2) These cities each have one top art and design college in China (there are only eight such colleges in China). In addition, the distributions of the colleges and universities at other levels in the two cities are similar.

The samples are randomly stratified and collected from the undergraduates of a design major between July 3 and August 18, 2016, in Hangzhou and Guangzhou. According to the classification of Chinese schools, schools are divided into three major levels: key universities or top universities, undergraduate colleges, and vocational schools. First, the schools are selected, and the design students are randomly selected from each school using student IDs. The reason for adopting this approach is that, Chinese design students must participate in the national unified entrance examination before they enter the institutions, thus, students are admitted from different parts of the country in accordance with their scores, which means that students from schools of the same rank in different parts of China show similarities. After the samples are complete, a network questionnaire link is sent to students in advance by E-Mail.

A total of 320 qualified students replied. After deleting samples with questionable responses (e.g., participants answered "Strongly Disagree" or "Strongly Agree" to all questions in the second section of the questionnaire), the number of valid observations is 278 .

\section{Demographic Data}

The first section of the valid questionnaires indicate that $58.4 \%$ of participants are female and $41.6 \%$ are male. The number of participants in each grade as a proportion of all participants: freshmen $25 \%$, sophomore $55.4 \%$, junior $15.6 \%$, and senior $4 \%$. A total of $48.4 \%$ of participants believe that social media platforms dedicated to film, television, and video are the most conducive to creativity and learning.

\section{Measurement}

The second section includes seven factors: adoption intention, perceived ease of use, perceived usefulness, capturing, challenging, broadening, and surrounding. 
The factor measurements of PEU and PU are developed from previous studies (Chen \& Li, 2010; Davis, 1989; Hsu \& Lin, 2008; Chan, 2014), with some scale items reworded to reflect the context of the social media tool, which includes 12 variables. Measurement for AI is developed from the study of Karahanna et al. (1999), Bhattacherjee (2001), and Chang and Zhu (2011), and includes 5 items.

The factor measurements of capturing, challenging, broadening, and surrounding are based on the Epstein Creativity Competencies Inventory for Individuals (ECCI-i), by Epstein et al. (2008). The items on the test are exemplars of typical behaviors within each of the four core competency areas, and ECCI-i has 28 items, which are evenly divided among the four competency subscales (Table 3). This research omits questions with meanings similar to ECCI-i, and extends the questions of variables, as based on reality. This portion includes 21 items.

All scale items use a 7-point Likert scale anchored between "strongly disagree" and "strongly agree". The scale items are listed in Table 3.

\section{DATA ANALYSES AND RESULTS}

\section{Data Analysis Methods}

The statistical analysis tool SAS9.4 is adopted for data analysis. First, this study describes the characteristics of the samples through descriptive analysis, according to the basic information of the samples. Second, this study divides the questionnaires into two groups according to response order, and identifies non-responses by chi-square testing. Third, factor analysis and canonical correlation analysis are conducted for the data collected in the second part of the questionnaire.

Canonical correlation analysis refers to the multivariate statistics analysis method, which uses the correlation of a canonical variate pair to reflect the overall correlation between two sets of indicators. The basic principle is, as follows: to understand the correlation between two groups of indicators on the whole, and two typical canonical variates using "With" and "Var" (linear combination of all variables in each variate group) are extracted. The correlation between each set is then used to reflect the overall correlation between the two groups of indicators. In this research, Var = usability dimension of social media, With = creative expression dimension, which are two canonical variates. The usability dimension of social media includes three factors: adoption intention, perceived ease of use, and perceived usefulness, while the individual creative expression dimension includes four factors: capturing, challenging, broadening, and surrounding.

\section{Factor Analysis Results}

Factor analysis is first conducted on the data collected in the second part, with the procedures of sample checking, assumption testing, and tests of appropriateness, reliability, validity, factor loading, and factor score.

Data and information for analysis have normal distribution, and conform to linear homogeneity. Analysis standards and results are, as follows:

Henry Kaiser (1974) introduced the Measure of Sampling Adequacy (MSA) of factor analytic data matrices. According to MSA, the appropriateness of the experimental data is tested. Based on Kaiser's (1974) point of view, if $\mathrm{KMO}<0.5$, it is not suitable for factor analysis; if the MSA of each factor of the experiment data is $>0.5$, and the MAS of each variable is $>0.5$, it is suitable for factor analysis. In all variables, the values of Cronbach's a are above 0.71 (Table 3), which are higher than the threshold level of 0.7, as suggested by Nunnally (1978). Composite reliability (CR) is a more rigorous estimate of reliability (Chin \& Gopal, 1995), and all the values are above 0.90, which meet the criterion for strong reliability. As recommended by Hair et al., the minimum factor loading of EFA is 0.5. The values of factor loadings are above 0.70 , and the average variance extracted (AVE) values of all factors are above 0.71 (Table 3). The results support the convergent validity of the measures (Fornell \& Larcker, 1981). 
EURASIA J Math Sci and Tech Ed

Table 3. Reliability convergent validity and factor analysis

\begin{tabular}{|c|c|c|c|c|c|c|c|}
\hline Variable & Measurement question & Loading & KMO & P-value & $\alpha$ & CR & AVE \\
\hline \multicolumn{3}{|c|}{ Adoption intention (Al) } & 0.719 & & 0.714 & 0.951 & 0.803 \\
\hline Al1 & I always try new social media tools & delete & & & & & \\
\hline $\mathrm{Al} 2$ & I plan to use new social media tools as learning tools & 0.707 & 0.753 & $<0.0001$ & & & \\
\hline $\mathrm{Al} 3$ & I advise students to use social media for learning in the future & 0.771 & 0.727 & $<0.0001$ & & & \\
\hline Al4 & I plan to capture creative inspiration through social media & 0.782 & 0.684 & $<0.0001$ & & & \\
\hline Al5 & I plan to improve my creativity through social media & 0.766 & 0.760 & $<0.0001$ & & & \\
\hline \multicolumn{3}{|c|}{ Perceived usefulness (PU) } & 0.816 & & 0.855 & 0.967 & 0.833 \\
\hline PU1 & Conducive to learning and creativity improvement & 0.713 & 0.749 & $<0.0001$ & & & \\
\hline PU2 & Improve learning and creative expression & 0.786 & 0.822 & $<0.0001$ & & & \\
\hline PU3 & Make my learning and creative expression more efficient & 0.741 & 0.828 & $<0.0001$ & & & \\
\hline PU4 & Good for team cooperation and communication & 0.761 & 0.726 & $<0.0001$ & & & \\
\hline PU5 & Help improve my ability to solve problems & 0.798 & 0.868 & $<0.0001$ & & & \\
\hline PU6 & Good for creative expression & 0.793 & 0.695 & $<0.0001$ & & & \\
\hline \multicolumn{3}{|c|}{ Perceived ease of use (PEU) } & 0.816 & & 0.853 & 0.901 & 0.837 \\
\hline PEU1 & It is easy to improve creativity through social media & 0.767 & 0.831 & $<0.0001$ & & & \\
\hline PEU2 & Most social media are easy to use & 0.812 & 0.805 & $<0.0001$ & & & \\
\hline PEU3 & Social media tools are flexible to use & 0.834 & 0.892 & $<0.0001$ & & & \\
\hline PEU4 & Social media tools allow me to capture inspiration easily & 0.867 & 0.789 & $<0.0001$ & & & \\
\hline PEU5 & Social media tools allow me to better acquire knowledge & 0.717 & 0.877 & $<0.0001$ & & & \\
\hline PEU6 & It is easier to share knowledge on social media & 0.718 & 0.895 & $<0.0001$ & & & \\
\hline \multicolumn{3}{|c|}{ Challenging $(\mathrm{CH})$} & 0.748 & & 0.841 & 0.959 & 0.773 \\
\hline $\mathrm{CH} 1$ & I will make sure to set attainable goals & 0.781 & 0.703 & $<0.0001$ & & & \\
\hline $\mathrm{CH} 2$ & I will sometimes try to solve some problems not easily solved & 0.782 & 0.762 & $<0.0001$ & & & \\
\hline $\mathrm{CH} 3$ & I am not afraid of learning new things & 0.837 & 0.745 & $<0.0001$ & & & \\
\hline $\mathrm{CH} 4$ & I will make sure to set ambitious goals & 0.767 & 0.799 & $<0.0001$ & & & \\
\hline $\mathrm{CH} 5$ & Continuous learning is vital for me & 0.731 & 0.748 & $<0.0001$ & & & \\
\hline $\mathrm{CH} 6$ & I like to occasionally solve difficult problems & 0.709 & 0.846 & $<0.0001$ & & & \\
\hline $\mathrm{CH} 7$ & I am not afraid of failure & 0.745 & 0.763 & $<0.0001$ & & & \\
\hline \multicolumn{3}{|c|}{ Surrounding (SU) } & 0.701 & & 0.809 & 0.945 & 0.749 \\
\hline SU1 & $\begin{array}{l}\text { I will look for a new environment and rethink when I have no clear } \\
\text { ideas }\end{array}$ & 0.700 & 0.785 & $<0.0001$ & & & \\
\hline SU2 & I will ponder a question in particular places & 0.792 & 0.812 & $<0.0001$ & & & \\
\hline SU3 & $\begin{array}{l}\text { I will sometimes contact different people to facilitate constructive } \\
\text { thinking }\end{array}$ & 0.811 & 0.661 & $<0.0001$ & & & \\
\hline SU4 & I manage my own pressure well & 0.783 & 0.665 & $<0.0001$ & & & \\
\hline SU5 & I will sometimes find new creativity from my dreams & 0.750 & 0.801 & $<0.0001$ & & & \\
\hline SU6 & I tend to record my ideas on social media tools on my phone & 0.783 & 0.783 & $<0.0001$ & & & \\
\hline \multicolumn{3}{|c|}{ Broadening (BR) } & 0.747 & & 0.744 & 0.978 & 0.782 \\
\hline BR1 & I always learn new things from different fields on the Internet & 0.766 & 0.763 & $<0.0001$ & & & \\
\hline BR2 & I tend to seek training opportunities on social media & 0.713 & 0.725 & $<0.0001$ & & & \\
\hline BR3 & I tend to expand my experiences through social media & 0.814 & 0.747 & $<0.0001$ & & & \\
\hline \multicolumn{3}{|c|}{ Capturing (CA) } & 0.601 & & 0.729 & 0.924 & 0.719 \\
\hline CA1 & I tend to record my new ideas on social media tools on my phone & 0.738 & 0.579 & $<0.0001$ & & & \\
\hline CA2 & I only read information in my own field & 0.726 & 0.655 & $<0.0001$ & & & \\
\hline CA3 & I don't like to solve difficult problems & 0.783 & 0.742 & $<0.0001$ & & & \\
\hline CA4 & I record new ideas with new social media all the time & 0.766 & 0.688 & $<0.0001$ & & & \\
\hline CA5 & I sometimes know nothing about topics in class & 0.714 & 0.743 & $<0.0001$ & & & \\
\hline
\end{tabular}

This research takes the above factors analysis results as IV and DV for CCA analysis, as shown in Table 4. 
Table 4. Factors analysis results as IV and DV

\begin{tabular}{|c|c|c|c|}
\hline Dimension & & Factor & Factor Score \\
\hline \multirow{3}{*}{$\begin{array}{c}\text { Usability } \\
\text { dimension } \\
\text { of social } \\
\text { media }\end{array}$} & IV1 & $\begin{array}{l}\text { Adoption } \\
\text { intention }\end{array}$ & $0.25532 * \mathrm{Al} 2+0.32466 * \mathrm{Al} 3+0.32892^{\star} \mathrm{Al} 4+0.3224^{\star} \mathrm{Al} 5$ \\
\hline & IV2 & $\begin{array}{l}\text { Perceived } \\
\text { usefulness }\end{array}$ & $0.23914 * P U 1+0.18446 * P U 2+0.21522^{*} P U 3+0.24949 * P U 4+0.24764 * P U 5+0.27864 * P U 6$ \\
\hline & IV3 & $\begin{array}{l}\text { Perceived } \\
\text { ease of use }\end{array}$ & $\begin{array}{c}0.14971^{*} \text { PEU1 + 0.24972*PEU2 + } 0.26879^{*} \text { PEU3 + 0.27042*PEU4 + } 0.20668^{*} \text { PEU5 + } \\
0.17687^{*} \text { PEU6; }\end{array}$ \\
\hline \multirow{4}{*}{$\begin{array}{c}\text { Creative } \\
\text { expression } \\
\text { dimension }\end{array}$} & DV1 & Challenging & $\begin{array}{c}\mathrm{CH} 1^{*} 0.12313+\mathrm{CH}^{*} 0.15562+\mathrm{CH}^{*} 0.25062+\mathrm{CH}^{*}{ }^{*} 0.12262+\mathrm{CH}^{*} 0.1759+\mathrm{CH}^{*} 0.17438+ \\
\mathrm{CH} 7^{*} 0.19511 ;\end{array}$ \\
\hline & DV2 & Surrounding & SU1*0.134 + SU2*0.17887+SU3*0.33039+SU4*0.23983+SU5*0.25071+SU6*0.13912; \\
\hline & DV3 & Broadening & $\mathrm{BR}^{*} 0.16613+\mathrm{BR} 2^{*} 0.29193+\mathrm{BR} 3^{\star} 0.31038$ \\
\hline & DV4 & Capturing & CA $1 * 0.36011+$ CA2*0.29489 + CA3*0.17159+CA4*0.20877+CA5*0.25014; \\
\hline
\end{tabular}

Table 5. Test of Multi-Collinearity

\begin{tabular}{rrccccc}
\hline \multicolumn{1}{c}{ Test variable } & Other variables & TOL & R Square & adject R & p-value \\
\hline DV1 & CH & SU BR CA & $0.76821,0.82148,0.77805$ & 0.440 & 0.422 & $<.0001$ \\
\hline DV2 & SU & CH BR CA & $0.61072,0.85724,0.60172$ & 0.296 & 0.273 & $<.0001$ \\
\hline DV3 & BR & CH SU CA & $0.56353,0.73972,0.60533$ & 0.184 & 0.157 & 0.000 \\
\hline DV4 & CA & CH SU BR & $0.73819,0.71811,0.83719$ & 0.410 & 0.390 & $<.0001$ \\
\hline IV1 & Al & PU PEU & $0.86582,0.86582$ & 0.033 & 0.011 & $<.0001$ \\
\hline IV2 & PU & AI PEU & $0.96807,0.96807$ & 0.135 & 0.116 & 0.001 \\
\hline IV3 & PEU & AI PU & $0.99836,0.99836$ & 0.161 & 0.143 & 0.000 \\
\hline
\end{tabular}

Table 6. Number of Canonical Function

\begin{tabular}{ccccc}
\hline & $\begin{array}{c}\text { Canonical } \\
\text { Correlation }\end{array}$ & $\begin{array}{c}\text { Squared Canonical } \\
\text { Correlation }\end{array}$ & \multicolumn{2}{c}{$\begin{array}{c}\text { Test of } \mathrm{H}_{\mathbf{0}}: \\
\text { The canonical correlations in the current row and all that follow are zero }\end{array}$} \\
\cline { 4 - 5 } & 0.658 & 0.433 & $\mathbf{F}$-Value & P-Value \\
\hline CF1 & 0.658 & 5.18 & $<.0001$ \\
\hline
\end{tabular}

\section{Canonical Correlation Analysis (CCA) Results}

According to CCA procedures, this study examines the sample size of the data; conducts assumption testing, as judged by the Shapiro-Wilk test; uses the PROC PLOT grammar of SAS to examine the linear homogeneity of IV and DV; uses Pearson Correlation Analysis and considers over $50 \%$ of the p-value $<0.05$ as the test of appropriateness; tests multi-collinearity using TOL to examine the collinearity of variables in the same group; uses regression equation to test IV and DV in same group, as shown in Table 5. Test results show that IV and DV in this research are free of collinearity.

Canonical Function (CF) Selection: in this research, Canonical Correlation generates the following variables: 3 VAR, 4 With, 3 CF. Only when simultaneously passing the Square Canonical Correlation, F-testing, and the Redundancy Index Measure, is CF established. Analysis shows that only CF1 passes. As show in Table 6, CF1: Square Canonical Correlation R2 $=0.433$, F-test $=5.18$, and $p<.0001$ redundancy index. For DV collection in CF1, $13.93 \%$ of the variance can be explained by With1, while Proportion $=0.1393>0.1$ and $17.42 \%$ variance can be explained by Var, Proportion= $0.1742>0.1$. The above index testing proves that CF1 is established.

Canonical Function Interpretation: Based on the above testing, the CF1 equation is obtained:

Creative expression dimension $=\operatorname{Var} 1=0.789^{*} \mathrm{CH}-0.399 * \mathrm{SU}+0.174 * \mathrm{BR}+0.395^{*} \mathrm{CA}$;

Usability dimension of social media $=$ With $1=0.097 * \mathrm{AI}+0.184 * \mathrm{PU}+0.896 * \mathrm{PEU}$;

After the equation is generated, use the correction between variables DV and IV, and IV and IV, i.e., Canonical Loading; use the value of Canonical correlation and standard criteria of $>0.3$, judge how well DV and IV can be explained by Var and With. If $<0.3$, then indicate with a dotted line in the research model. As show in Figure 2, there is no percentage for a variable that can be explained. 


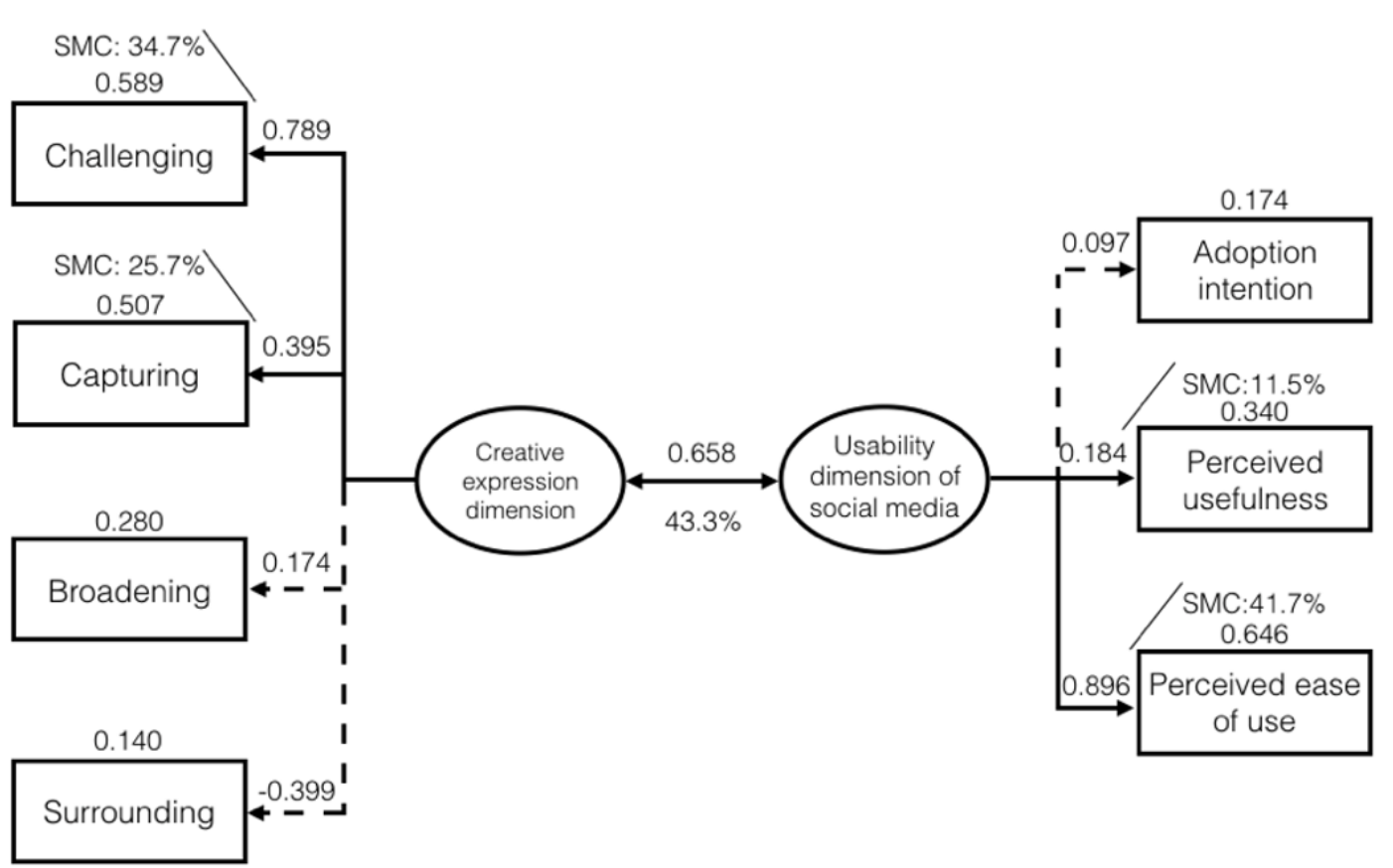

Figure 2. Creative expression dimension VS the usability dimension of social media

Results show that the usability dimension of social media can explain $43.3 \%$ of the total variance of the creative expression dimension (Squared Canonical Correlation); $34.7 \%$ of the variance for challenging in one set is explained by the usability dimension of social media; $25.7 \%$ of the variance for capturing is explained by the usability dimension of social media; $11.5 \%$ of the variance for perceived usefulness is explained by the dimension of creative expression; $41.7 \%$ of the variance for perceived ease of use is explained by the dimension of creative expression.

\section{DISCUSSION AND IMPLICATIONS}

The results of this study show that social media is correlated with creative expression. In particular, perceived ease of use and perceived usefulness have significant and positive correlation with capturing and challenging. In other words, students majoring in design can use social media to promote their creativity and influence the two aspects of challenging and capturing. In addition, individual creativity has positive influence on perceived ease of use and perceived usefulness; $41.7 \%$ of the variance of perceived ease of use can be explained by creative expression; $11.5 \%$ of the variance of perceived usefulness can be explained by creative expression. Hence, students with higher creativity have fewer obstacles in their use of social media.

Stefania Manca and Maria Ranieri (2016) deemed that, as a new technological tool, social media provides us with the functions of recording, storage, instant sharing, and exchange, which facilitate the capture of inspiration. This point is consistent with the significant and positive correlation between the usability dimension of social media and capturing. In addition, the usability dimension of social media is significantly correlated with challenging, which is consistent with the research findings of Boyd (2001). When students use social media, their intention of self-expression and challenging will be affected; in other words, some students will compare themselves with their peers or have the psychology to challenge their peers who share their content or work. This finding reminds teachers to design various activities that can enhance the challenging or capturing nature of students during their education of social media, thus, better facilitating education.

This study finds that the usability dimension of social media has positive influence on broadening; however, such influence is not significant. Though many researchers believe that social media is conducive to accumulating and sharing knowledge (Luckin et al., 2009; Mao, 2014); based on the findings of this study, pure accumulation of knowledge does not enhance creativity. In other words, when social media is used in a study, we must deliberately accumulate knowledge, and absorb and convert the knowledge during accumulation; otherwise, such accumulation does not have obvious effect to enhance creativity. Additionally, studies on the negative effects of fragmented learning support the findings of this study. Fragmented learning is a type of multi-task learning, with the side-effect that it prevents one from obtaining the things he/she truly wants to learn (Craik, 2010), and requires students to have a complete knowledge system, as well as strong study desire and skills. Simply put, when using social media for study, students must have clear goals and clearly understand what they can obtain through the 
information provided by social media. Otherwise, the rich information available on social media is just information for students.

The usability dimension of social media has negative influence on surroundings; however, such influence is not significant. This finding causes this researcher to reflect. Boyd (2001) found that the use of social media would bring about many negative effects, such as sensitivity to the real surrounding world. The creativity theories of Guilford and Csikszentmihalyi pointed out that surrounding environment has influence on creativity. If users overly use social media and ignore the interaction between social media and offline content, or the real world, sensitivity to their surroundings and the inspiration gained from the real world will be reduced. Thus, users shall reasonably utilize their time on the Internet, in order to balance the diversity of the channels to gain creative inspiration. This finding reminds the designers and operators of social media to enhance the function of interactions with the real world, such as the design of social media with VR.

\section{STUDY LIMITATIONS AND FUTURE RESEARCH DIRECTIONS}

This study proposes a social media constructing creativity theoretical model to study the correlation between the usability dimension of social media and the individual creativity of students majoring in design. Although our findings provide meaningful implications, this study has several limitations that should be addressed in the future. The perceived ease of use, perceived usefulness, and adoption intention in this study are merely the basic usability dimensions of social media, and are unable to reflect all usability dimensions as a whole. In this light, other factors, such as self-expression and the usability motive, may be further analyzed. At the same time, this study aims to understand the connection between the usability dimension of social media and individual creativity without testing other intermediary factors, such as personality and demographic variables, and explores the influence of different types of social media. These are issues for follow up studies to explore in the future.

\section{REFERENCES}

Abel, T. D. (2015). Design Education: Teaching Design Science By Incorporating Eye-tracking Data Into Undergraduate Visual Communication Design Studios.

Bhattacherjee, A. (2001). Understanding information systems continuance: An expectation-confirmation model. MIS Quarterly, 25(3), 351-370.

Boyd, D. M. (2001). Taken out of context American teen sociality in networked publics (Doctoral Thesis). University of California, Berkeley.

Campbell, D. T., \& Fiske, D. W. (1959). Convergent and Discriminant Validation by the Multitrait-Multimethod Matrix. Psychological Bulletin, 56, 81-105.

Chai, J. X., \& Fan, K. K. (2016). Mobile inverted constructivism: Education of interaction technology in social media. Eurasia Journal of Mathematics Science and Technology Education, 12(5), 1425-1442. doi:10.12973/eurasia.2016.1522a

Chang, H. J. (2014). Adoption of e-book among college students: The perspective of an integrated TAM. Computers in Human Behavior, 41, 471-477. doi.org/10.1016/j.chb.2014.09.056.

Chang, Y. P., \& Zhu, D. H. (2011). Understanding social networking sites adoption in china: A comparison of preadoption and post-adoption. Computers in Human Behavior, 27(5), 1840-1848. doi:10.1016/j.chb.2011.04.006

Chen, S. C., \& Li, S. H. (2010). Consumer adoption of e-service: Integrating technology readiness with the theory of planned behavior. African Journal of Business Management, 4(16), 3556-3563.

Chin, W. W., \& Gopal, A. (1995). Adoption intention in GSS: Relative importance of beliefs. Database Advances, 26(2), 42-64.

Craik, H. (2010). Cognitive surplus: Creativity and generosity in a connected age -- clay shirky. International Journal of Advertising, 29(5), 835. doi:10.2501/S0265048710201488.

Creswell, J. W. (2014). Research design: Qualitative, quantitative, and mixed methods approaches (4thed.). Thousand Oaks, CA: Sage Publications, Inc.

Csikszentmihalyi, M. (1975), Beyond Boredom and Anxiety, Jossey-Bass. San Francisco, CA.

Csikszentmihalyi, M. (1990). Flow : the psychology of optimal experience(1st ed.). NY: Harper \& Row.

Csíkszentmihályi, M. (1996). Flow and the psychology of discovery and invention. NY: Harper Collins. Chicago.

Davis, F.D. (1989). Perceived usefulness, perceived ease of Use, and user acceptance of information technology. MIS, Q. 13(3), 319-340. 
Epstein, R. (1990) Generativity Theory and Creativity. In Runco, M.A. and Albert, R.S. (eds.), Theories of Creativity. Sage, Newbury Park, CA, pp.116-40.

Epstein, R. (1996). Cognition, creativity, and behavior: Selected essays. Westport, CT: Praeger.

Epstein, R. (1999). “Generativity Theory”. In Runco, M.A., Pritzker, S. Encyclopedia of Creativity. Academic Press.

Epstein, R., \& Phan, V. (2012). Which competencies are most important for creative expression? Creativity Research Journal, 24(4), 278. doi:10.1080/10400419.2012.726579

Epstein, R., Kirshnit, C. E., Lanza, R. P., \& Rubin, L. C. (1984). "Insight" in the Pigeon: Antecedents and Determinants of an Intelligent Performance. Nature, 308(5954), 61-62. doi:10.1038/308061a0. PMID 6700713.

Epstein, R., Schmidt, S. M., \& Warfel, R. (2008). Measuring and training creativity competencies: Validation of a new test. Creativity Research Journal, 20(1), 7-12. doi:10.1080/10400410701839876

Fornell, C., \& Larcker, D. F. (1981). Structural equation models with unobservable variables and measurement errors. Journal of Marketing Research, 18(1), 39- 50.

Fullagar, C. J., Kelloway, E. K. (2009). Flow at work: an experience sampling approach. Journal of Occupational and Organizational Psychology, 82(3), 595-615. doi:10.1348/096317908×35790

Gelb, D. (2015). Social Media, Constructivism and Design Studio: Lessons Learned.

Gu, C., Hu, B. Y., Ngwira, F. F., Jing, Z., \& Zhou, Z. (2016). The effect of general creative personality and freedom of task choice on adolescents' social creativity. The Journal of Creative Behavior, 50(2), 132-149. doi:10.1002/jocb.74

Guler, K. (2015). Social media-based learning in the design studio: A comparative study. Computers $\mathcal{E}$ Education, 87, 192-203. doi:10.1016/j.compedu.2015.06.004.

Hsu, C. L., \& Lin, C. C. (2008). Acceptance of blog usage: The roles of technology acceptance, social influence and knowledge sharing motivation. Information and Management, 45(1), 65-74.

Jones, M., \& Gelb, D. (2010). Course Co-Creation vs. Course Management: Wikis as a Potential Alternative to Traditional Learning Management Systems. T. Kidd \& I. Chan (Ed.) Wired for Learning: An Educators Guide to Web 2.0, eds. (pp.179-194) Charlotte, NC: Information Age Publications.

Kaiser, H. F. (1974). An index of factorial simplicity. Psychometrika, 39, 31-36.

Karahanna, E., Straub, D. W., \& Chervany, N. L. (1999). Information technology adoption across time: A crosssectional comparison of pre-adoption and post- adoption beliefs. MIS Quarterly, 23(2), 183-213.

Kozbelt, A., Dexter, S., Dolese, M., Meredith, D., \& Ostrofsky, J. (2015). Regressive imagery in creative ProblemSolving: Comparing verbal protocols of expert and novice visual artists and computer programmers. The Journal of Creative Behavior, 49(4), 263-278. doi:10.1002/jocb.64

Lim, C. K. (2015). Designers are Makers: Interdisciplinary Curriculum in a Digital Design Studio.

Manca, S., \& Ranieri, M. (2016). "Yes for sharing, no for teaching!": Social media in academic practices. The Internet and Higher Education, 29, 63-74. doi:10.1016/j.iheduc.2015.12.004

Mardia, K. V., Kent, J. T., \& Bibby, J. M. (1979). Multivariate Analysis. Academic Press.

Moran, M., Seaman, J., \& Tinti-Kane, H. (2012). Blogs, Wikis, Podcasts and Facebook: How Today's Higher Education Faculty Use Social Media. Pearson Learning Solutions and Babson Survey Research Group.

Nakamura, J., \& Csikszentmihalyi, M. (2014). The concept of flow. In Flow and the foundations of positive psychology (pp. 239-263). Springer Netherlands.

Nunnally, J. C. (1978). Psychometric theory. New York: McGraw-Hill.

Peppler, K. A., \& Solomou, M. (2011). Building creativity: Collaborative learning and creativity in social media environments. On the Horizon, 19(1), 13-23. doi:10.1108/10748121111107672

Solis, B. \& Breakenridge, D. (2009). Putting the Public Back in Public Relations: How Social Media Is Reinventing the Aging Business of PR. FT Press.

Zhuang, Z. J. (2008). The cognition and users satisfaction relationship of instant message software.

\section{http://www.ejmste.com}

